\title{
Assessment of Reliability of Mixing Process in Diverse Mixers
}

\author{
Paweł KRZACZEK, Paweł SOBCZAK*, Ewa STAMIROWSKA-KRZACZEK, Kazimierz ZAWIŚLAK, Grzegorz MAJ, \\ Wioletta ŻUKIEWICZ-SOBCZAK, Wiesław PIEKARSKI, Jolanta KRÓLCZYK
}

\begin{abstract}
Homogeneity of fodder blends is one of the primary fodder blend quality criteria. Inadequate mixing of fodder ingredients may cause insufficient growth of livestock and unsuccessful medical treatment in the case of healing fodder. Majority of fodder producers make use of the information contained in the fodder blend technical dossier for the purpose of target mixing parameters. However, average mixing time, that is very often specified, does not reflect the specific nature of a given fodder blend. Apart from the fodder blend construction parameters, physical properties of raw materials used for production purposes, in particular disintegration degree, fodder blend discharge manner, filling degree have an impact upon the homogeneity of mixing. The research on the homogeneity of mixing in various fodder producers has proven the necessity to control this stage of production.
\end{abstract}

Keywords: fodder; homogeneity; microtracers; mixing

\section{INTRODUCTION}

Out of a number of significant factors that have an impact upon the quality of the mixing process, the characteristic features of mixed materials need to be underlined. It is easiest to mix ingredients that show equal dimensions of particles. Excessive disintegration has an adverse impact upon both the technological process and the feeding process in a variety of aspects. In the case of varied dimensions of particles, larger particles are positioned in the upper part of the system and the smaller ones - in the lower part of the mixing chamber. In the case of varied density, secondary segregation may occur in the course of the mixing process [1-3].

Physical properties of raw materials, namely water content, average size of particles, inlet angle and outlet angle as well as the shape of grains have a considerable impact upon the mixing process. Furthermore, the kinetics of the process is influenced by the process condition (time) and construction parameters of the mixing device $[4,5]$. The research on the homogeneity of the fodder blend conducted by Królczyk (2014) [6] has allowed to develop equation formulae for the mixing process regression, which address raw materials content and physical properties of raw materials. The effects of nonhomogeneity of the blend matter to feeding livestock. The research conducted by McCoy et al. (1994) [7], aiming at experiments on three different kinds of fodder, beginning with insufficiently mixed one, intermediary blend, and ending with the target one, has proven that growth of chicken depends on the fodder.

In the course of operations of mixers, a number of technical factors have an impact upon the technological processes. Notwithstanding the common application of various kinds of mixing chambers, the processes ongoing in the mixing chambers have not been ultimately identified; therefore the research on the assessment of the impact of the construction and technical parameters upon the quality of the blend is still an outstanding issue [8].

The method based on microtracers as referred to in the norm [9] is the prevailing method of assessment of mixing efficiency. The chemical analysis of samples and subsequent comparison of quantities of substances in respective samples under consideration are other known methods [10, 11]. Zhang et al. (2011) [12] have suggested a new method of analysing indicators in the fluidised bed, that comes forward with integration of microwave warming with infrared thermovision. As a result of continual warming of indicators, they underwent continual monitoring in the fluidised bed.

An important problem in the production of industrial feeds at various stages is dustiness and excessive noise. Research on the possibility of noise reduction by increasing the area and elimination of partition walls was proposed by Pascuzi et al. 2017 [13]. The level of pollination at various stages of industrial feed production was also examined. The largest amount of dust was noted during grinding. At the mixing stage, the level of dustiness was in the right standards [14].

The objective of the research has been to assess the process of mixing selected blends characteristic of diverse mixer constructions installed at fodder producers.

\section{METHODOLOGY}

Various types of mixers installed at fodder procedures have undergone the analysis. Respective mixers differed in terms of construction of stirrers or size. In every mixer, the mixing process was operated in compliance with the operations manual contained in the Technical and Operational Documentation (TOD). The following mixers underwent the analysis:

- AMA Mixer (marked as A for the analysis purposes)standard capacity of one chamber is $0.5 \mathrm{~m}^{3}$. The mixing time recommended by the manufacturer is from 300 to 480 $\mathrm{s}$. The mixing time applied by the fodder producer is $300 \mathrm{~s}$. - Single Shaft Preblend Mixer (marked as B for the analysis purposes), has the capacity of $1.5 \mathrm{~m}^{3}$ and two tripping brackets of 0.9 and $0.6 \mathrm{~m}$ in diameter, according to the Technical and Operational Documentation. The rotation speed (according to the Technical and Operational Documentation) - $36 \mathrm{rpm}$. Filling time depends on the filling manner, the mixing time is recommended not to exceed $180 \mathrm{~s}$. According to the Technical and Operational Documentation, the discharging time is $60 \mathrm{~s}$.

- Cone Vertical Mixer (marked as $\mathrm{C}$ for the analysis purposes) with the upper ingredients inlet is used for producing pre-blends. The single inlet volume amounts to 
$500 \mathrm{~kg}$, the mixing time -420 s., and the discharging time is approximately $70 \mathrm{~s}$.

- MPW-1000 (marked as D for the analysis purposes) the single shaft horizontal mixer with a bracket mixer of $2.2 \mathrm{~m}^{3}$ in capacity, a central inlet and outlet, equipped with an engine of $11 \mathrm{~kW}$ in power output with a motoreducer. The mixer has 4 brackets of $1.2 \mathrm{~m}$ in outer diameter 0.06 $\mathrm{m}$ in width. The mixer is filled in automatically by means of weighing reservoirs in which the content of the fodder blend is determined. According to the measurements, the dosing time is approximately 300 seconds. The crevice between the bottom of the chamber and the mixer bracket is approximately $0.005 \mathrm{~m}$. The mixer performs $25 \mathrm{rpm}$. The recommended mixing time is $360 \mathrm{~s}$.

- UNI-MIX 1500 Mixer (marked as E for the analysis purposes)-the low speed screw mixer with a screw crosswise positioned in relation to the ground level. The capacity of the mixer was $1500 \mathrm{~kg}$ whereas the mixing time - 900 s., the discharging time - $720 \mathrm{~s}$.

The research on the homogeneity of mixing was conducted by means of three methods: in compliance with the ASAE (S303.4) Standard describing test procedures for assessment of the mixing capacity of cyclical mixers. In compliance with that procedure, before the blend is being mixed, microtracers are added to the blend, the microtracers being iron filings in the quantity of $50 \mathrm{~g}$ per a ton of raw material, and subsequently 10 samples taken from each batch (the control group) [15] (sampling procedure in conformity with the norm), and the analysis was repeated three times in the case of each blend in respective mixers. In compliance with the mixing regularity Standard, samples of $80 \mathrm{~g}$ in weight, that should contain approximately 100 particles, given the relevant tracer concentration, are collected.

In the case of the MPW-1000 mixer, the homogeneity was assessed by means of defining the salt content in the samples according to the method by Mohr in compliance with the norm [16]. After having defined the salt content, standard calculations of the variability coefficient were performed. In this case 15 blend samples were taken for the purpose of assessing homogeneity of the process. Two mixing times, namely 360 seconds and 480 seconds, underwent the analysis. It was assumed to apply the constant input volume of $995 \mathrm{~kg}$ of corn meal and $5 \mathrm{~kg}$ (i.e., $0.5 \%$ ) of salt. Before the target measurement, the filling time, the discharging time were analysed and measured, which allowed to define the sampling time, namely the commencement moment and sampling frequency. The original samples in the number of 15 per each batch weighed $250 \mathrm{~g}$ each and were collected from the discharge outlet underneath the mixer in the intervals of 10 seconds. The samples of $100 \mathrm{~g}$ in weight were used for defining the salt content.

However, in the case of the UNI-MIX 1500 mixer, the procedure of defining the content of various elements in the samples was performed. For the purpose of the analysis, the energy dispersive x-Ray Fluorescence Spectroscopy Shimadzu EDX-7000 Energy (the elements: K, P, S, Si). The method of analysing Na-U quantity and quality was used for analysing the fodder content. The measurements were performed in ambient air. In respect of each fodder batch, 10 measurements were performed and the resulting figures were averaged. The effective measuring time took $360 \mathrm{~s}$ per sample. The typical fodder blend grower 2 for pigs was used.

The resulting figures underwent statistical tests in order to define the variability coefficient $(\mathrm{CV})$ as the mixing process quality assessment criterion. According to the literature $[17,18]$ and on the grounds of the technical features of mixers described by manufacturers, the following requirements were set out:

- for mixers producing ready-made blends (mixing capacity $1: 10.000$ ) variability coefficient $C V 15 \%$,

- for pre-blend mixers (mixing capacity 1:100.000) variability coefficient $C V 10 \%$.

Before the research on blend homogeneity was analysed, selected physical properties that characterise the blended material had been defined and presented in Tab. 1.

Table 1 Physical properties of the mixtures presented in the studies

\begin{tabular}{|l|c|c|c|c|c|c|}
\hline \multicolumn{1}{|c|}{ Material } & Moisture content $/ \%$ & $\begin{array}{c}\text { Bulk density / } \\
\mathrm{kg} / \mathrm{m}^{3}\end{array}$ & $\begin{array}{c}\text { Shaken density / } \\
\mathrm{kg} / \mathrm{m}^{3}\end{array}$ & Chute angle / ${\text { Angle of repose } /{ }^{\circ}}^{\text {Average particle size / mm }}$ \\
\hline Mixture & 7.95 & 677.1 & 742 & 32 & 32 \\
\hline Premix & 2.6 & 1170 & 1244 & 30 & 0.52 \\
\hline Corn meal & 13.2 & 752.7 & 779.7 & 25 & 0.56 \\
\hline Masterbatch & - & - & - & - & 0.952 \\
\hline Grover 2 & 11.9 & 604 & 692 & 26 & - \\
\hline
\end{tabular}

\section{RESULTS}

From Tab. 2 to Tab. 6 show the resulting figures for the homogeneity of mixing in respective mixers. In conformity with the applied methods, the adequate homogeneity is proven by blends for which the variability coefficient is below $15 \%$. The A mixer, given the input of $750 \mathrm{~kg}$, was characteristic of sufficient mixing. All the resulting values of the variability coefficient were below $15 \%$ (Tab. 2).

The method using microtracers, which has been described, requires a specific precision in terms of calculation, separation and dosing of microtracers, the volume of which is measured in terms of nanometers. This method is assumed to be relevant for laboratory marking; however, in terms of production processes, it is hard to be applied without an adequately equipped laboratory. Matuszek (2012) [1] came to similar conclusions on the assessment of homogeneity of fodder blends by means of microtracers.

Tab. 3 presents the resulting figures for the pre-blend produced in the B mixer. According to the Technical and Operational Documentation, the mixing time is suggested to take $180 \mathrm{~s}$. According to the analysis, the variability coefficient was above $10 \%$, which proved insufficient mixing. It is noticeable that in two cases, its value is in excess of $16 \%$. The output pre-blend is not homogenous and it is necessary to change the mixing parameters.

Similar discrepancies in the homogeneity of fodder blends were obtained by Matuszek (2012) [1] while 
analysing the mixing degree of chicken blends at the fodder production plant in which the rotary vane horizontal mixer of $4000 \mathrm{~kg}$ in capacity was installed (the analysis was conducted on the mixer filled in up to $50 \%$ ). In respect to two different fodder blends, the mixing time of 210 seconds allowed to obtain the target homogeneity of mixing. That time having been shortened down to 180 seconds caused insufficient mixing of raw materials alike the time having been lengthened up to 240 seconds, which resulted in stratification of the mixed blend. The subsequent analyses conducted on the same type of a mixer [19] but for diverse blends, proved that the homogeneity of mixing depended on physical properties of a blend to a great extent. Equal homogeneity was obtained in result of the mixing time of 210 seconds and 240 seconds. The time of 180 seconds was too short to assure the target homogeneity.

Table 2 Number of microtracers in the samples according to replicates taken after the mixing process during the unloading of mixer A, batch $750 \mathrm{~kg}$

\begin{tabular}{|c|c|c|c|}
\hline \multirow{2}{*}{$\begin{array}{c}\text { Number of } \\
\text { sample }\end{array}$} & \multicolumn{3}{|c|}{ Repetitions } \\
\cline { 2 - 4 } & I & II & III \\
\hline 1 & 123 & 100 & 96 \\
\hline 2 & 106 & 93 & 115 \\
\hline 3 & 95 & 98 & 103 \\
\hline 4 & 91 & 94 & 118 \\
\hline 5 & 110 & 106 & 105 \\
\hline 6 & 97 & 109 & 88 \\
\hline 7 & 96 & 114 & 102 \\
\hline 8 & 96 & 107 & 117 \\
\hline 9 & 95 & 120 & 119 \\
\hline 10 & 80 & 106 & 129 \\
\hline Average & 98.9 & 104.7 & 109.2 \\
\hline$S D$ & 11.666 & 8.603 & 12.435 \\
\hline$C V / \%$ & 11.796 & 8.2168 & 11.387 \\
\hline
\end{tabular}

Table 3 Number of microtracers in the trials according to replicates taken after the mixing process in mixer $\mathrm{B}$, in which the pre-mix was produced, the charge of $1000 \mathrm{~kg}$

\begin{tabular}{|c|c|c|c|}
\hline \multirow{2}{*}{$\begin{array}{c}\text { Number of } \\
\text { sample }\end{array}$} & \multicolumn{3}{|c|}{ Repetitions } \\
\cline { 2 - 4 } & I & II & III \\
\hline 1 & 84 & 81 & 104 \\
\hline 2 & 107 & 93 & 96 \\
\hline 3 & 90 & 91 & 105 \\
\hline 4 & 117 & 115 & 128 \\
\hline 5 & 127 & 118 & 90 \\
\hline 6 & 132 & 117 & 102 \\
\hline 7 & 93 & 115 & 99 \\
\hline 8 & 119 & 138 & 110 \\
\hline 9 & 88 & 109 & 124 \\
\hline 10 & 109 & 90 & 85 \\
\hline Average & 106.6 & 106.7 & 104.3 \\
\hline$S D$ & 17.148 & 17.417 & 13.59 \\
\hline$C V / \%$ & 16.086 & 16.323 & 13.029 \\
\hline
\end{tabular}

Other authors, Djuragic et al. (2009) [17], conducted the assessment of the impact of the disintegration degree upon the mixing sufficiency by means of the horizontal bracket mixer for 300 seconds of mixing. The analysis proves the considerable impact of the disintegration degree, and in particular the content of fair particles in the blend upon the mixing efficiency.

The rotary speed of stirrers, apart from physical properties of the blend, has a considerable impact upon the mixing process. The conducted assessment of the impact of technical parameters, inter alia the rotary speed of a stirrer, [20] has indicated that the optimal rotary speed for the bracket mixer is $100 \mathrm{rpm}$, for which $C V$ has been obtained at the level of $9.6 \%$. Increase in the rotary speed up to $120 \mathrm{rpm}$ has caused the variability coefficient to rise up to $14.3 \%$ and the rotary speed to go down to $80 \mathrm{rpm}$ to $12 \%$.

Tab. 4 presents the resulting figures of the assessment of homogeneity obtained for the pre-blend produced in the $\mathrm{C}$ mixer. In the case of both tests, the $C V$ coefficient has been below $15 \%$, which is indicative of sufficient mixing of the fodder.

Table 4 Number of microtracers in subsequent trials in a $\mathrm{C}$ mixer for mixing

\begin{tabular}{|c|c|c|}
\hline Test / mixing time & I & II \\
\hline 1 & 101 & 88 \\
\hline 2 & 86 & 66 \\
\hline 3 & 100 & 66 \\
\hline 4 & 114 & 67 \\
\hline 5 & 101 & 69 \\
\hline 6 & 107 & 87 \\
\hline 7 & 94 & 93 \\
\hline 8 & 99 & 67 \\
\hline 9 & 88 & 73 \\
\hline 10 & 106 & 80 \\
\hline Average & 99.6 & 75.6 \\
\hline$S D$ & 8.5531 & 10.48 \\
\hline$C V / \%$ & 8.5875 & 13.862 \\
\hline
\end{tabular}

The homogeneity of mixing may also be assessed at the fodder production plants by means of defining the salt content in samples.

Table $\mathbf{5}$ The average salt content from three replicates from the $\mathrm{D}$ mixer

\begin{tabular}{|c|c|c|}
\hline Sample & Mixing time 360 s & Mixing time 480 s \\
\hline 1 & 0.54 & 0.53 \\
\hline 2 & 0.57 & 0.58 \\
\hline 3 & 0.54 & 0.51 \\
\hline 4 & 0.62 & 0.51 \\
\hline 5 & 0.53 & 0.59 \\
\hline 6 & 0.55 & 0.55 \\
\hline 7 & 0.52 & 0.51 \\
\hline 8 & 0.53 & 0.55 \\
\hline 9 & 0.54 & 0.54 \\
\hline 10 & 0.52 & 0.54 \\
\hline 11 & 0.54 & 0.54 \\
\hline 12 & 0.56 & 0.58 \\
\hline 13 & 0.51 & 0.59 \\
\hline 14 & 0.62 & 0.56 \\
\hline 15 & 0.53 & 0.46 \\
\hline Average & 0.55 & 0.54 \\
\hline$S D$ & 0.03 & 0.04 \\
\hline$C V / \%$ & 5.95 & 6.83 \\
\hline
\end{tabular}

Tab. 5 presents the resulting figures obtained in the case of the D mixer upon having added $0.5 \%$ of salt. The analyses were conducted in respect to two different mixing times (360 seconds and 480 seconds). According to the resulting figures, the target mixing efficiency was achieved within the assumed mixing times. However, the mixing time having been lengthened by 120 seconds (up to 480 seconds) caused the variability coefficient to deteriorate, notwithstanding the satisfactory results that were achieved.

Tab. 6 presents the results of defining the elements in the samples in the case of the E mixer. The suggested method of assessment of the homogeneity allows assessing the mixing efficiency quickly without the necessity to apply microtracers. The procedure of assessment is the same, namely calculation of the $C V$ coefficient, and the percentage share of selected elements is a variable. According to the resulting figures, the applied parameters of mixing were relevant, the value of $C V<15 \%$ was obtained for all the selected elements. 
Table 6 The content of selected elements in the samples from $\mathrm{E}$ mixer

\begin{tabular}{|c|c|c|c|c|}
\hline Test / mixing time & $\mathrm{S} / \%$ & $\mathrm{~K} / \%$ & $\mathrm{P} / \%$ & $\mathrm{Si} / \%$ \\
\hline 1 & 5.283 & 25.184 & 4.131 & 5.324 \\
\hline 2 & 5.707 & 26.329 & 3.829 & 5.84 \\
\hline 3 & 5.437 & 28.012 & 3.73 & 5.516 \\
\hline 4 & 5 & 27.357 & 3.636 & 5.36 \\
\hline 5 & 5.43 & 27.532 & 3.65 & 5.21 \\
\hline 6 & 4.663 & 23.64 & 3.405 & 4.49 \\
\hline 7 & 5.468 & 26.587 & 3.596 & 5.466 \\
\hline 8 & 5.243 & 29.428 & 3.563 & 5.72 \\
\hline 9 & 4.647 & 32.44 & 3.247 & 5.752 \\
\hline 10 & 5.239 & 30.197 & 3.929 & 5.885 \\
\hline Average & 5.2117 & 27.671 & 3.6716 & 5.4563 \\
\hline$S D$ & 0.3466 & 2.5354 & 0.253 & 0.41 \\
\hline$C V / \%$ & 6.6499 & 9.1629 & 6.8908 & 7.5141 \\
\hline
\end{tabular}

The assessment of the homogeneity of mixing becomes the critical point within the industrial fodder production quality assurance system. Nonhomogeneity is indicative of poor quality of the fodder blend. The conducted assessment of the homogeneity of blends makes it plausible to state that the method is useful for analysing the process of mixing in the production plants. It provides for fast reaction in the course of the technological process counteracting production of blends showing non-standard parameters [2].

\section{CONCLUSIONS}

The conducted research has allowed arriving at the following conclusions:

- The choice of the mixing time and the filling time of a mixer applied in accordance with the Technical and Operational Documentation should be tested in terms of the homogeneity of mixing.

- The information contained in the Technical and Operational Documentation should specify the physical properties of the blend for which the mixing time is recommended (density, the size of the blend particles, water content).

- In the case of the insufficient homogeneity, it is necessary to adjust the mixing time and the mixer filling in level.

- In the case of a very good homogeneity of the blend, it is necessary to undertake measures in order to assess the plausibility of shortening the mixing time, which may improve energy efficiency of the process.

- The method of assessment of the homogeneity of mixing by means of the Shimadzu equipment is the alternative method of assessment of the homogeneity of fodder. The fast assessment, precision and accuracy of the analyses account for advantages of that method. These advantages prove that it is necessary to conduct further research on the possibility of automating the assessment of homogeneity of mixing using computer methods, which will allow for continuous control of the production process.

\section{Acknowledgements}

The research was conducted at the Centre of Engineering Studies of the State School of Higher Education in Chełm within the project "Laboratory of Environmental Studies CSI PWSZ in Chełm" co-financed by the European Fund of Regional Development (part of the Operational Programme Eastern Poland) 2007-2013.

\section{REFERENCES}

[1] Matuszek, D. (2012). Analiza procesu mieszania paszy dla drobiu w przemysłowej wytwórni pasz. Agricultural Engineering, 2(136), 213-220.

[2] Zawiślak, K., Sobczak, P., \& Wełdycz, A. (2012). Mixing as $\mathrm{CCP}$ in the production of industrial feed. Journal of Central European Agriculture,13(3), 554-562. https://doi.org/10.5513/JCEA01/13.3.1088

[3] Rocha, A. G., Montanhini, R. N., Dilkin, P., Tamiosso, C. D., \& Mallmann, C.A. (2015). Comparison of different indicators for the evaluation of feed mixing efficiency. Animal Feed Science and Technology, 209, 249-256. https://doi.org/10.1016/j.anifeedsci.2015.09.005

[4] Heidenreich, E. \& Strauch, W. (2000). Decisive factors for solids mixing process in compound feed production. Part 2. Feed Magazine, 7-8, 286-292.

[5] Siiriä, S. \&Yliruusi, J., (2009). Determining a value for mixing: Mixing degree. Powder Technology. 196, 309-317. https://doi.org/10.1016/j.powtec.2009.08.009

[6] Królczyk, J. (2014). An attempt to predict quality changes in a ten-component granular system. Tehnicki VjesnikTechnical Gazette, 21(2), 255-261.

[7] McCoy, R. A., Behnke, K. C., Hancock, J. D., \& McEllhiney, R. R. (1994). Effect of mixing uniformity on broiler chick performance. Poultry Science, 73, 443-451. https://doi.org/10.3382/ps.0730443

[8] Marczuk, A., Caban, J., Savinykh, P., Turubanov, N., \& Zyryanov, D. (2017). Maintenance research of a horizontal ribbon mixer. Eksploatacja I Niezawodnosc - Maintenance and Reliability, 19(1), 121-125. https://doi.org/10.17531/ein.2017.1.17

[9] ASAEANSI/ASAE S303.4 2007. Test procedure for solidsmixing equipment for animal feed.

[10] Putier, F. (2001). Assessment of homogeneity of compound feed. Feed Magazine, 3, 98-108.

[11] Ferraris, C. F. (2001). Concrete mixing methods and concrete mixers: state of the art. Journal of Research of the National Institute of Standards and Technology, 106(2), 391399. https://doi.org/10.6028/jres.106.016

[12] Zhang, Y., Zhong, W., \& Jin, B., (2011). New method for the investigation of particle mixing dynamic in a spout-fluid bed. Powder Technology, 208(3), 702-712. https://doi.org/10.1016/j.powtec.2011.01.011

[13] Pascuzzi, S. \& Santoro, F. (2017). Analysis of possible noise reduction arrangements inside olive oil mills. A case study. Agriculture, 7(10), 88. https://doi.org/10.3390/agriculture7100088

[14] Sobczak, P. Zawiślak, K., Żukiewicz-Sobczak, W., Wróblewska, P., Adamczuk, P., Mazur, J., \& Kozak, M. (2015). Organic dust in feed industry. Polish Journal of Environmental Study, 24(5), 2177-2183. https://doi.org/10.15244/pjoes/42019

[15] PN-EN ISO 6497:2005 - Animal feeding stuffs - Sampling.

[16] PN-A-79011-7:1998 Koncentraty spożywcze. Metody badań. Oznaczenie zawartości chlorku sodowego. (in polish)

[17] Djuragic, O., Levic, J., Sredanovic, S., \& Levic, L. (2009). Evaluation of homogeneity in feed by method of microtracers. Archiva Zootechnica, 12(4), 85-91.

[18] Eisenberg, D. (1998). The use of Microtracers F (colored uniformly sized iron particles) in coding the presence of coccidiostats in poultry feeds. Practical implications. Zootechnica International, 46-50.

[19] Matuszek, D. (2013). The analysis of homogeneity of industrial fodder for cattle. Journal of Research and Application in Agricultural Engineering, 58(1), 118-121. 
[20] Sobczak, P., Zawiślak, K., Panasiewicz, M., Mazur, J., \& Oniszczuk, T. (2012). The quality of the mixing process depending on selected technical parameters. TEKA Commission of Motorization and Energetics in Agriculture, 12(2), 199-202.

\section{Contact information:}

Paweł KRZACZEK, PhD

Department of Power Engineering and Transportation, University of Life

Sciences in Lublin, Poland,

Głęboka 28, 20-612 Lublin, Poland

E-mail: pawel.krzaczek@up.lublin.pl

Paweł SOBCZAK, prof.,

(Corresponding author)

Department of Food Engineering and Machinery, University of Life Sciences in

Lublin, Poland

Głęboka 28, 20-612 Lublin, Poland

E-mail: pawel.sobczak@up.lublin.pl

Ewa STAMIROWSKA-KRZACZEK, PhD,

Institute of Agricultural Sciences, State School of Higher Education in Chełm, Poland

54 Pocztowa Street, 20-100 Chełm, Poland

E-mail: ekrzaczek@pwsz.chelm.pl

Kazimierz ZAWIŚLAK, prof.,

Department of Food Engineering and Machinery, University of Life Sciences in

Lublin, Poland,

Głęboka 28, 20-612 Lublin, Poland

E-mail: kazimierz.zawislak@up.lublin.pl

Grzegorz MAJ, prof.

Department of Power Engineering and Transportation, University of Life

Sciences in Lublin, Poland,

Głeboka 28, 20-612 Lublin, Poland

E-mail: grzegorz.maj@up.lublin.pl

Wioletta ŻUKIEWICZ-SOBCZAK, prof

Pope John Paul II State School of Higher Education in BialaPodlaska, Poland Sidorska 95/97, 21-500 BiałaPodlaska, Poland

E-mail: wiola.zukiewiczsobczak@gmail.com

Wiesław PIEKARSKI, prof.

Department of Power Engineering and Transportation, University of Life

Sciences in Lublin, Poland,

Głęboka 28, 20-612 Lublin, Poland

E-Mail: wieslaw.piekarski@up.lublin.pl

Jolanta KRÓLCZYK, prof.,

Department of Manufacturing Engineering and Production Automation, Faculty

of Mechanical Engineering, Opole University of Technology,

Mikolajczyka Street 5, 45-271 Opole, Poland

E-mail: j.krolczyk@po.opole.pl 